DOI 10.15393/j9.art.2016.3941

УДК 821.161.1.09"1917/1992"

Марина Владимировна Заваркина

Петрозаводский государственный университет

(Петрозаводск, Российская Федераиия)

mvnikulina@mail.ru

\title{
АНДРЕЙ ПЛАТОНОВ В ПОИСКАХ ЖАНРА *
}

Аннотация. В статье рассматривается проблема жанра в творчестве А. Платонова. Оспаривается установившаяся в платоноведении точка зрения о «внежанровом мышлении» писателя. Анализируются основные жанры его творчества: стихотворение, публицистическая и литературнокритическая статья, рассказ, повесть, роман, пьеса, сценарий, сказка. Если взглянуть на «жанровую карту» творчества А. Платонова, то можно увидеть определенный, «стратегический» выбор писателем того или иного жанра как способа выразить себя. Как показано в статье, из-за проблем с цензурой А. Платонов одни и те же идеи варьировал снова и снова, пробовал воплотить их в разных жанрах, пытаясь таким образом пробиться к своему читателю. В художественном наследии А. Платонова можно обнаружить некую жанровую систему, позволяющую обозначить периодизацию его творчества в зависимости от жанровых предпочтений на том или ином отрезке времени. Жанровое разнообразие при наличии определенного круга повторяющихся идей подтверждает взгляд на произведения писателя как на единый текст.

Ключевые слова: А. Платонов, жанр, жанровое мышление, жанровая стратегия, роман, повесть, рассказ, статья, сказка, стихотворение

B

1924 году в журнале «Русский современник» появилась статья Б. Эйхенбаума «В поисках жанра», автор которой отстаивал необходимость сознательной «установки» любого художника на жанр, писал о кризисе литературы и необходимости новых жанров (см.: [18, 295]).

В это же время А. Платонов только-только входил в советскую литературу и находился в своих «поисках жанра». Он начинал со сборника стихов и публицистики, затем пробовал себя в разных прозаических жанрах - от рассказа до романа. Особое место среди его произведений занимают пьесы, киносценарии, сказки, а также литературно-критические статьи. Категория жанра с самого начала была основополагающей проблемой творчества А. Платонова. В платоноведении же, 
наоборот, утвердилась ошибочная, на наш взгляд, точка зрения о «внежанровом» мышлении писателя $[14,162]$.

Художественная природа произведений А. Платонова чаще всего рассматривалась в связи с его философией (работы Н. Корниенко, Т. Богданович, Н. Великой), уделялось внимание взаимосвязи стиля и жанра (работы С. Голубкова, Н. Корниенко), ставился акцент на отдельных категориях поэтики жанра: композиции и специфике художественного времени и пространства (работы Г. Галасьевой, Н. Великой, А. Семеновой), своеобразии сюжета (работы Н. Малыгиной, Л. Фоменко), проблеме характера (статьи Л. Гимильяновой), наконец в 2005 году вышла первая и единственная обобщающая работа - монография С. И. Красовской «Художественная проза А. П. Платонова: жанры и жанровые процессы» [11].

В платоноведении в большей степени изучена «вторая природа» жанра произведений писателя, прежде всего, утопия и антиутопия. Исследователи предлагают и другие номинации: метаутопия, какотопия. Зарубежные слависты, с одной стороны, вводят специальный термин - «антиутопическая стратегия» (см., напр.: [12]), с другой - даже не пытаются разграничить жанры утопии и антиутопии: «Platonov's position in this tradition is pecular: his mature works, such as Cevengur, are neither fully utopian nor fully anti-utopian»". Название монографии Г. Гюнтера «По обе стороны утопии» [5] демонстрирует сложность антиутопической, или, точнее сказать, - метаутопической - стратегии А. Платонова.

М. Золотоносов находит в творчестве писателя какотопию и называет А. Платонова «первым какореалистом» $[6,88]$. Какотопия - это разновидность антиутопии, дословно с греческого (како́ то́тоৎ) переводится как плохое, злое место; страна зла. Однако существовал еще «мовизм» В. Катаева (от фp. mauvais «плохой, дурной»), противостоявший официозу соцреализма. А. Платонов не писал какотопий, потому что не пытался ставить диагнозы, чем чаще всего и занимается какотопия как жанр. Его целью было не изображение советской России как плохого, дурного, злого места, а честное отражение действительности. Советский мир был и надеждой и болью писателя. Соблюдать политический и художественный баланс 
ему было сложно, отсюда все проблемы с цензурой, но, главное, - в произведениях писателя важен диалог, а не монолог, сомнение, а не уверенность. Очень часто в его текстах сомнение сменяется робкой надеждой и снова сомнением. Произведения А. Платонова называли «пасквилем» на советскую действительность, хотя они прежде всего свидетельствовали о сложной, противоречивой позиции Платонова-художника и Платонова-гражданина. Проследить действие этого механизма, создающего «эффект амбивалентного, “лирико-сатирического” авторского отношения к изображаемому» $[19,14],-$ на сегодняшний день остается важной, чуть ли не главной задачей платоноведения.

А. Платонов чаще всего заявлял жанр уже на начальном этапе работы над текстом: в рукописи или машинописи. Авторское наименование жанра можно обнаружить и в творческих анкетах, как, например, в «Анкете группкома Московского товарищества писателей» 1933 года: «За последние три года мною написано следующее: “Шарманка” - пьеса, "Высокое напряжение” - пьеса, "Море юности” - повесть; “Хлеб и чтение” - повесть; “14 Красных избушек” - пьеса; “Любовь к дальнему” - рассказ; “Мусорный ветер” - рассказ; “Счастливая Москва" - роман» ${ }^{2}$. Однако исследователи часто не обращают внимания на авторское определение жанра и дают другое, по их мнению, более соответствующее поэтике произведения. Например, повесть «Котлован» нередко называют романом. В «Котловане», действительно, можно обнаружить черты романной сюжетно-композиционной структуры (обширная система персонажей, несколько самостоятельных сюжетных линий, открытый финал и т. д.). Сближаясь с производственным романом 1920-х - 1930-х годов, «Котлован», по авторскому замыслу, все-таки является философской повестью о поиске истины.

Творческий путь А. Платонова традиционно делят на десятилетия (1920-е, 1930-е, 1940-е гг.). Н. В. Корниенко предлагает и другие, условные, названия: воронежский, «чевенгурский», «московский» периоды [9, 178-179]. Периодизацию творчества писателя можно сделать, если отталкиваться и от его жанровых предпочтений. Несмотря на то, что литературная биография 
писателя началась в 1918 году с публикации в журнале «Железный путь» рассказа «Очередной», принято считать, что А. Платонов проявился, прежде всего, как поэт. Единственный сборник стихотворений, вышедший при его жизни (в 1922 г. в Краснодаре), назывался «Голубая глубина», хотя А. Платонов писал стихи и позже: например, на рубеже 1926-1927 годов. он готовил поэтический сборник «Поющие думы», частично состоявший из стихотворений «Голубой глубины», а также включавший в себя новые стихотворения 1922-1926 годов. Параллельно молодой поэт активно занимался журналистикой: печатался в газетах и журналах Воронежа («Воронежская коммуна», «Красная деревня», «Красный воин», «Огни», «Красный луч», «Железный путь», «Искусство и театр», «Зори», «Путь коммунизма»), а также в центральных журналах («Красная нива», «Кузница», «Октябрь мысли», «Пламя»). По мнению В. В. Эйдиновой, «жанровая форма платоновских корреспонденций соотносилась с ситуацией дня - военной, экономической, культурной. Если в более спокойные месяцы 1920-го года он выступал не только как публицист, но и как лирик, прозаик, то в “жаркое” время года он преимущественно - публицист, агитатор, разъясняющий положение момента, зовущий рабочих и крестьян к решению той или иной конкретной задачи» $[17,102]$. Молодому начинающему писателю была важна живая реакция на современные события, и он пишет статьи на злободневные темы: Гражданская война, международная и внутренняя политика, современная литература и искусство, история. В свое время Л. А. Шубин [16] и С. Г. Бочаров указывали на то, что идеи Платонова, выраженные в публицистике, находят дальше свое выражение в платоновской прозе: «...опускаясь в художественный мир <..> они встречались и сталкивались как разные противоречивые друг другу начала» $[1,12]$. Исследователи пытались проследить сложное взаимодействие идей Платонова-публициста и Платоноваписателя. Так, Л. Ф. Гилимьянова, анализируя особенности изображения характера в творчестве А. Платонова, отметила, во-первых, связь характера с жанровыми особенностями произведений писателя, во-вторых, выстроила типологию характеров в зависимости от тех основных идей, которые 
реализуются в них и которые пришли из платоновской публицистики воронежского периода [4].

А. Платонов работал «по нарастающей». Жанр статьи в какой-то степени подготовил его к жанру рассказа. Складывается ощущение, что писателю стало «тесно» в рамках публицистического жанра, и он обратился к художественной реализации своих идей, которые требовали новой жизни в живой ткани художественного текста. Сильным элементом в структуре жанра стала фантастика: в начале 1920-х годов. А. Платонов создает свой собственный фантастический мир. В рассказах «Маркун» (1921), «Невозможное» (1921), «Сатана мысли» (1922), «Приключения Баклажанова» (1922), «Потомки солнца» (1922), «Рассказ о многих интересных вещах» (1923), «Лунные изыскания (Рассказ о “кирпиче”)» (1926), «Родоначальники нации или беспокойные происшествия» (1927) он создает образ героя-испытателя, нередко самоучки (Маркун, Вогулов, Баклажанов, Матиссен, Попов, Крейцкопф, Кирпичников), а главной темой становится тема ответственности ученого за последствия своего открытия. Переходным этапом стала повесть «Эфирный тракт» (1927), в работе над которой, по мнению В. Васильева, «умирал утопический писатель и рождался реалистический художник» $[2,67]$. Н. В. Корниенко считает, что повесть стала «важным этапом в поиске “индекса персонажа" (определение Л. Гинзбург) <...> той верысомнения, под знаком которой оформляется в повести герой: ставший центральным для всего последующего творчества Платонова» $[8,54]$. Повесть не была опубликована при жизни писателя, остальные же повести 1920-х годов («Епифанские шлюзы», «Город Градов», «Сокровенный человек», «Ямская слобода») вышли в 1927-1928 годы.

В отличие от рассказов в повестях А. Платонова более развернутым становится сюжет, увеличивается количество персонажей, меняется проблематика. Появляется образ «сокровенного» человека, ставший своеобразной эмблемой его творчества. Первое название повести "Сокровенный человек» (1927) - «Страна философов». Именно из этой «страны» выйдут будущий философ Вощев (повесть «Котлован»), «душевный бедняк» (повесть «Впрок»), ученые романа 
«Счастливая Москва». Более того, с этого времени жанр повести становится излюбленным жанром в творчестве писателя: именно повесть, а не рассказ, по нашему мнению, возьмет на себя роль метажанра в жанровой системе А. Платонова ${ }^{3}$. В то время, когда советская литература была активно нацелена работать в жанрах производственного романа или очерка с производства, Платонов обращается к традиционному жанру русской литературы - повести, хотя роман как «неготовый» жанр, казалось, больше подходил для отображения становящейся действительности. Как в свое время рассказ стал той почвой, на которой вызревала повесть А. Платонова, так и повесть, в свою очередь, явилась ступенью к жанру романа. После «Сокровенного человека» писатель работает над повестью «Строители страны», из которой вырастет роман «Чевенгур» (1926-1928), первоначально имевший жанровое обозначение «повесть» ${ }^{4}$. Повести первой половины 1930-х гг. («Котлован», «Впрок», «Ювенильное море», «Хлеб и чтение», «Джан») станут художественной лабораторией для создания второго романа писателя - «Счастливая Москва» (1934-1936). Именно в этих повестях складывается матрица будущих героев московского романа А. Платонова: Москвы Честновой, Сарториуса, Самбикина, Божко.

Традиционные черты жанра повести (аналитизм, изображение важных, судьбоносных событий в жизни героя, сосредоточенность на взаимоотношениях человека и мира), а также открытость и синтетичность ее жанровой структуры позволили А. Платонову, с одной стороны, использовать содержательные и формальные возможности других жанров (очерка, производственного романа, хроники), с другой - совершенно иначе, чем это было предписано советской литературе, осветить тему строительства социализма, оставаясь верным гуманистическому пафосу и духовным исканиям русской классической литературы.

Жанровый синтетизм лучше всего виден на примере повести «Впрок» (1930), в которой можно обнаружить сочетание компонентов трех жанров: повести, хроники, очерка, а также метажанровый диалог утопии и антиутопии. Повесть «Ювенильное море» (1931) демонстрирует сложность антиутопической 
стратегии А. Платонова: «вторую природу» жанра этого произведения можно определить не просто как метаутопию, a, скорее, как квазиутопию (дословно - «как бы утопия», «подделка под утопию»).

Из повестей 1930-х годов только повесть «Впрок» будет опубликована при жизни писателя. Скандальная репутация повести, первым читателем которой стал И. Сталин, перечеркнет все надежды А. Платонова быть услышанным. Жесткая реакция «главного читателя» страны удивила А. Платонова: «Нет ведь ни одного писателя, имеющего такой подход в тайники душ и вещей, как я. Добрая половина моего творчества помогает партии видеть всю плесень некоторых вещей...» (цит. по: [15, 283-284]). С этого момента тексты Платонова начнут подвергаться еще более тщательной цензуре, чем после скандала с публикацией рассказа «Усомнившийся Макар» (1929). Многие замыслы так и останутся незаконченными: «Технический роман» (до нас дошла только первая часть возможной трилогии — «Хлеб и чтение» <1931>), повесть «Инженер» (другой вариант - «Инженеры»), романы «Македонский офицер» и «Путешествие из Ленинграда в Москву в 1937 году», роман о Стратилате. Параллельно с прозой писатель работает над киносценариями и пьесами, в которых - уже в драматургической форме - пытается высказать те же идеи, что и в повестях 1930-х годов («Шарманка», «Высокое напряжение», «14 Красных избушек» и др.). Практически по всем своим повестям 1920-х годов А. Платонов планировал написать киносценарии. В свое время М. Горький предлагал писателю переделать роман «Чевенгур» в пьесу. Этим планам не суждено было воплотиться в жизнь. Зато пьесы и сценарии стали источниками некоторых повестей А. Платонова 1930-х годов: киносценарий «Машинист» сыграл важную, если не ключевую роль в творческой истории «Котлована» (1930); сюжет повести «Джан» (1934-1935) первоначально разрабатывался Платоновым в драматургической форме, центром пьесы должна была стать история отца Назара Чагатаева ${ }^{5}$. По мнению Н. В. Корниенко, в художественной лаборатории трагедии «14 красных избушек» вызревал и роман «Счастливая Москва» $[7,24]$, тоже не вышедший при жизни писателя. 
Постоянные отказы в публикации снова приводят А. Платонова к жанру рассказа. Писатель использует теперь обратный прием: повести переделывает в рассказы. Так было, например, с повестью «Хлеб и чтение», которую А. Платонов превратил в рассказ «Родина электричества» для публикации в 1939 году в журнале «Индустрия социализма» ${ }^{6}$ В 1937 году выходит, наконец, сборник рассказов «Река Потудань» - первая крупная публикация А. Платонова за последнее десятилетие. Но «правду таланта» не скрыть, и вслед за сборником появляется очередная разгромная статья, на этот раз А. Гурвича, в которой писатель обвинялся в «религиозном душеустройстве».

Во второй половине 1930-х годов А. Платонов обращается к литературно-критическим статьям - следствие сотрудничества писателя с журналом «Литературный критик». Книга статей «Размышления читателя» так и не вышла в свет, в том числе и из-за травли, которую устроили журналу, и из-за последующего его закрытия в 1940 году. Сам Платонов признавался, что литературно-критические статьи помогали ему расти над собой, что ему было легче «совершенствоваться в своей работе», «пробиваясь вперед сначала хотя бы одной “публицистической мыслью”»".

Во время войны писатель был военным корреспондентом, реальность снова обратила его к жанру рассказа. Лаконичная форма этого жанра, предполагающего описание одного-двух важных в жизни героя событий, ограниченность по времени дали возможность писателю сосредоточиться на сегодняшнем трагическом моменте жизни - войне. Искренность Платонова-художника, его нетривиальный взгляд на судьбу человека военного времени не могли не найти отклик в сердцах читателей. В 1942 году вышел сборник «Одухотворенные люди», сокращенный и переработанный, но вполне благосклонно встреченный критикой ${ }^{9}$ В 1943 году А. Платонов написал рассказ «Возвращение», где попытался показать, как сложно человеку, пережившему все ужасы войны, жить прежней, мирной, жизнью. Это был честный взгляд на человека (не столько на воина, сколько именно на человека), его психологию. Однако время требовало иных героев, изображения благородных защитников отечества, поэтому рассказ Платонова был признан клеветой на советского солдата. 
В последние годы жизни А. Платонов обращается к детской прозе: пишет рассказы для детей и сборники русских и башкирских сказок. Он и раньше писал литературные сказки и рассказы для детей, но теперь, не имея возможности публиковаться, сосредотачивается на этих жанрах, которые становятся единственно возможными для связи с читателем. Однако дело не только в цензуре. Сказки и рассказы для детей стали теми жанрами, в которых в полной мере воплотилась платоновская утопия. Все сокровенные идеи, высказанные писателем во «взрослых» жанрах и так и не дошедшие до читателя, теперь «перекочевали» в жанры детской литературы. В. Вьюгин считает, что обратившись «К фольклорному жанру, Платонов в определенной степени достиг своей цели, на каком-то этапе он завершил поиск истины: в сказках он точно знал, о чем нужно говорить с читателем. Извечная открытость платоновских текстов, их жанровая аморфность неожиданно сменились предельной завершенностью» $[3,391]$. Серьезность этих идей критики не могли не заметить, поэтому детскую прозу А. Платонова отказываются принимать именно как детскую, вплоть до сегодняшнего времени: «...дети в 1930-1940-е годы изображаются Платоновым “полными людьми”, способными воплотить лучшие чаяния человечества» $[13,215]$.

Творческий путь А. Платонова, его жанровые пристрастия, парадоксальный синтез жанрового разнообразия и жанрового постоянства ${ }^{10}$ могут свидетельствовать о наличии у писателя не только сугубо жанрового мышления, но и определенной жанровой стратегии. Жанр был ключевой категорией творчества А. Платонова, «посредником» между ним и читателем. Писатель варьировал, пересказывал снова и снова свои идеи в разных жанрах, искал те, с помощью которых он мог бы пробиться к читателю, вести с ним полноценный диалог. Начав с лирики, публицистики и малых прозаических жанров, А. Платонов «наращивает силы» и приходит к жанру романа, но постоянная цензура и автоцензура вынуждают писателя «спуститься» с этой вершины, «разбиться на осколки», вернуться к малой прозе. Жанровое разнообразие в творчестве А. Платонова при наличии определенного круга повторяющихся идей подтверждает взгляд на произведения писателя как на единый текст. 


\section{Примечания}

* Исследование выполнено по гранту Министерства образования и науки России «Новые источниковедческие и текстологические исследования русской словесности XIX-XX вв.» (№ 34.1126).

1 «Позиция Платонова в этой традиции характерна: его зрелые работы, такие, как “Чевенгур", не являются полностью утопическими, как и антиутопическими» (David M. Bethea. The Shape of Apocalypse in Modern Russian Fiction. Princeton University Press, 1989. Р. 158. Цит. по: [20, 79]).

2 Андрей Платонов: воспоминания современников: материалы к биографии. М.: Современный писатель, 1994. С. 318.

3 По мнению С. И. Красовской, метажанром в жанровой системе А. Платонова является рассказ $[11,21]$.

4 Подробнее см.: $[3,103]$.

5 Подробнее см.: Малая проза Андрея Платонова / публикация Е. И. Колесниковой // Творчество Андрея Платонова: исследования и материалы. Кн. 2. СПб.: Наука, 2000. С. 257; Платонов А. П. Записные книжки. Материалы к биографии. М.: ИМЛИ РАН, 2006. С. 382.

6 Подробнее см.: [10, 740].

7 Гурвич А. Андрей Платонов // Андрей Платонов: воспоминания современников. С. 358-413.

8 Платонов А. Возражение без самозащиты (По поводу статьи А. Гурвича «Андрей Платонов») // Андрей Платонов: воспоминания современников. С. 415.

9 Подробнее см.: Платонов А. П. Усомнившийся Макар: рассказы 1920х годов. Стихотворения. М.: Время, 2011. С. 540.

10 Согласимся с С. И. Красовской, что обнаруживаемое в творчестве писателя жанровое постоянство «связано с постоянством его художественных идеалов» $[11,19]$.

\section{Список литературы}

1. Бочаров С. Г. «Вещество существования» // Андрей Платонов: мир творчества. - М.: Современный писатель, 1994. - С. 10-46.

2. Васильев В. Андрей Платонов. Очерк жизни и творчества. - М.: Современник, 1982. - 230 с.

3. Вьюгин В. Ю. Андрей Платонов: поэтика загадки. Очерк становления и эволюции стиля. - СПб.: РХГИ, 2004. - 440 с.

4. Гилимьянова Л. Ф. Проблема характера в творчестве А. П. Платонова // Поэтика русской прозы XX века: межвуз. сб. науч. тр. - Уфа, 1995. - C. 115-123. 
5. Гюнтер Г. По обе стороны утопии. Контексты творчества А. Платонова. М.: Новое литературное обозрение, 2012. - 216 с.

6. Золотоносов М. Андрей Платонов: первооткрыватель какотопии // Восстание масс: сборник. - СПб.: Мидгард, 2005. - С. 86-99.

7. Корниенко Н. В. Творческая биография и текстология А. П. Платонова (в художественной лаборатории писателя): автореф. дис. ... канд. филол. наук. - М., 1992. - 38 с.

8. Корниенко Н. В. История текста и биография А. П. Платонова (19261946) // Здесь и теперь. - 1993. - № 1. - 320 с.

9. Корниенко Н. В. Основной текст Платонова 30-х годов и авторское сомнение в тексте // Современная текстология: теория и практика. M., 1997. - С. 178-179.

10. Корниенко Н. В. От «Родины электричества» К «Техническому роману», и обратно: метаморфозы текста Платонова 1930-х гг. // «Страна философов» Андрея Платонова: проблемы творчества. - М.: ИМЛИ РАН, Наследие, 2000. - Вып. 4. - С. 739-744.

11. Красовская С. И. Художественная проза А. П. Платонова: жанры и жанровые процессы. - Благовещенск: Изд-во БГПУ, 2005. - 392 с.

12. Мерк А. К проблеме антиутопических стратегий в романе «Чевенгур» // «Страна философов» Андрея Платонова. - М.: Наследие, 1995. Вып 2. - С. 134-140.

13. Хрящева Н. П. Утопия детства А. Платонова. Из наблюдений над поэтикой рассказов 1930-х - 1940-х годов // Модели мироздания и трагическая судьба русской литературы XIX - нач. XXI века. Художественный и мемуарный дискурс: мат-лы IX Межд. науч. конференции. - Ульяновск: УлГТУ, 2012. - С. 204-216.

14. Чаликова В. Утопия рождается из утопии: эссе разных лет. - London: Overseas publ. interchange, 1992. - 217 c.

15. Шенталинский В. Рабы свободы. В литературных архивах КГБ. - М.: Парус, 1995. - 398 с.

16. Шубин Л. Андрей Платонов // Шубин Л. Поиски смысла отдельного и общего существования. Об Андрее Платонове. Работы разных лет. М.: Советский писатель, 1987. - С. 187-230.

17. Эйдинова В. В. Энергия стиля. О русской литературе XX века. - Екатеринбург: Гуманитарный университет, 2009. - 328 c.

18. Эйхенбаум Б. Литература: теория, критика, полемика. - Л.: Прибой, 1927. - $300 \mathrm{c}$.

19. Яблоков Е. Принцип художественного мышления А. Платонова «и так, и обратно» в романе «Чевенгур» // Филологические записки. - Воронеж, 1999. - Вып. 13. - С. 14-27.

20. Mørch A. J. The Novelistic Approach to the Utopian Question: Platonov's "Čevengur" in the Light of Dostoevskij's Anti-Utopian Legacy. - Oslo, 1998. - 289 p. 
Marina V. Zavarkina

Petrozavodsk State University

(Petrozavodsk, Russian Federation)

mvnikulina@mail.ru

\section{ANDREI PLATONOV IN SEARCH OF THE GENRE}

Abstract. The article studies the problem of genre in the literary works of A. Platonov. The viewpoint on the author's manner of thinking as "genre busting" that is very popular in Platonov Studies is argued here. The article analyzes the main genres of his creative work: verses, a publicistic and literarycritical article, a story, a short novel, a novel, a play, a script, a fairy tale. The diversity of genres used by the author represents a certain way of self-expression chosen by the author strategically. As it is shown in the article, because of the problems with censorship A. Platonov modified the same ideas trying to introduce them in different genres for the purpose of applying to his readers. In the artistic heritage of A. Platonov it is possible to detect a genre system that allows us to outline the periods of his creative work, according to his genre preferences at a particular point in time. Genre diversity in the presence of a certain range of recurrent ideas confirms the viewpoint of the writer's works as one text.

Keywords: A. Platonov, genre, genre thinking, genre strategy, novel, short story, story, article, fairy tale, poem

\section{References}

1. Bocharov S. G. «Veshchestvo sushchestvovaniya» ["Substance of Existence"]. Bocharov S. G. Andrey Platonov: mir tvorchestva [Bocharov S. G. Andrei Platonov: The World of Creativeness]. Moscow, Sovremennyy pisatel' Publ., 1994, pp. 10-46.

2. Vasil'ev V. Andrey Platonov: ocherk zhizni i tvorchestva [Andrei Platonov: An Essay on Life and Creativity]. Moscow, Sovremennik Publ., 1982. 230 p.

3. V'yugin V. Yu. Andrey Platonov: poetika zagadki. Ocherk stanovleniya $i$ evolyutsii stilya [Andrei Platonov: The Poetics of Mystery. An Essay on the Formation and Evolution of Style]. St. Petersburg, The Russian Christian Humanitarian Institute Publ., 2004. 440 p.

4. Gilim'yanova L. F. Problema kharaktera v tvorchestve A. P. Platonova [The Problem of Character in the Works of A. P. Platonov]. Poetika russkoy prozy XX veka [The Poetics of Russian Prose of the 20th Century]. Ufa, 1995, pp. 115-123.

5. Gyunter G. Po obe storony utopii. Konteksty tvorchestva A. Platonova [On Both Sides of Utopia: Contexts of Andrei Platonov's Creativity]. Moscow, Novoe literaturnoe obozrenie Publ., 2012. 216 p.

6. Zolotonosov M. Andrey Platonov: pervootkryvatel' kakotopii [Andrei Platonov: The Discoverer of Cacotopia]. Vosstanie mass: sbornik [The Revolt of the Masses: Digest]. St. Petersburg, Midgard Publ., 2005, pp. 86-99. 
7. Kornienko N. V. Tvorcheskaya biografiya i tekstologiya A. P. Platonova ( $v$ khudozhestvennoy laboratorii pisatelya). Avtoref. dis. ... kand. filol. nauk [The Creative Biography and Textual Criticism by A. P. Platonov (in the Artistic Laboratory of the Writer). PhD. philol. sci. diss. abstract]. Moscow, 1992. $38 \mathrm{p}$.

8. Kornienko N. V. Istoriya teksta i biografiya A. P. Platonova (1926-1946) [History of the Text and the Biography of A. P. Platonov (1926-1946)]. Zdes' i teper', 1993, no. 1.320 p.

9. Kornienko N. V. Osnovnoy tekst Platonova 30-kh godov i avtorskoe somnenie $\mathrm{v}$ tekste [The Principle Text of Platonov of the 1930s and the Author's Doubts in the Text]. Sovremennaya tekstologiya: teoriya i praktika [Modern Textual Criticism: Theory and Practice]. Moscow, 1997, pp. 178-179.

10. Kornienko N. V. Ot «Rodiny elektrichestva» k «Tekhnicheskomu romanu», i obratno: metamorfozy teksta Platonova 1930-kh gg. [From the "Motherland of Electricity" to the "Industrial Novel", and Back Again: The Metamorphosis of the Text of Platonov of the 1930s]. «Strana filosofov» Andreya Platonova: problemy tvorchestva ["Country of Philosophers" by Andrei Platonov: The Problems of Creative Work]. Moscow, A. M. Gorky Institute of World Literature of Russian Academy of Sciences Publ., Nasledie Publ., 2000, vol. 4, pp. 739-744.

11. Krasovskaya S. Khudozhestvennaya proza A. P. Platonova: zhanry i zhanrovye protsessy [The Fiction of A. P. Platonov: Genres and Genre Processes]. Blagoveshchensk, Blagoveshchensk State Pedagogical University Publ., 2005. 392 p.

12. Merk A. K probleme antiutopicheskikh strategiy v romane "Chevengur» [More on the Problem of Anti-Utopian Strategies in the Novel "Chevengur"]. «Strana filosofov» Andreya Platonova ["Country of Philosophers" by Andrei Platonov]. Moscow, Nasledie Publ., 1995, vol. 2, pp. 134-140.

13. Khryashcheva N. P. Utopiya detstva A. Platonova. Iz nablyudeniy nad poetikoy rasskazov 1930-kh - 1940-kh godov [Utopia of Childhood by A. Platonov. Based on the Examination of the Poetics of Short Stories of the 1930s-1940s]. Modeli mirozdaniya i tragicheskaya sud'ba russkoy literatury XIX - nachala XXI veka. Khudozhestvennyy i memuarnyy diskurs [The Models of the Universe and the Tragic Fate of Russian Literature of the 19th - Early 21 st Centuries. An Art and Memoir Discourse]. Ul'yanovsk, Ulyanovsk State Technical University Publ., 2012, pp. 204-216.

14. Chalikova V. Utopiya rozhdaetsya iz utopii. Esse raznykh let [Utopia Is Born from Utopia. Essays of Different Years]. London, Overseas Publications Interchange, $1992.217 \mathrm{p}$.

15. Shentalinskiy V. Raby svobody. V literaturnykh arkhivakh KGB [Slaves of Freedom. In the Literary Archives of the KGB (Committee for State Security)]. Moscow, Parus Publ., 1995. 398 p.

16. Shubin L. Andrey Platonov [Andrei Platonov]. Shubin L. Poiski smysla otdel'nogo i obshchego sushchestvovaniya. Ob Andree Platonove. Raboty raznykh let [Shubin L. The Search for a Sense of Individual and Colletive Existence. About Andrei Platonov. Works of Different Years]. Moscow, Sovetskiy pisatel' Publ., 1987, pp. 187-230. 
17. Eydinova V. V. Energiya stilya. O russkoy literature XX veka [Style Energy. On Russian Literature of the 20th Century]. Ekaterinburg, Gumanitarnyy universitet Publ., 2009. 328 p.

18. Eykhenbaum B. Literatura: teoriya, kritika, polemika [Literature: Theory, Criticism, Dispute]. Leningrad, Priboy Publ., 1927. 300 p.

19. Yablokov E. Printsip khudozhestvennogo myshleniya A. Platonova «i tak, i obratno» v romane "Chevengur» [The Principle of Platonov's Artistic Thinking "And This Way, and Back Again" in the Novel "Chevengur"]. Filologicheskie zapiski. Voronezh, 1999, vol. 13, pp. 14-27.

20. Mørch A. J. The Novelistic Approach to the Utopian Question: Platonov's "Čevengur" in the Light of Dostoevskijs Anti-Utopian Legacy. Oslo, 1998. 289 p.

Дата поступления в редакиию: 30.08.2016 